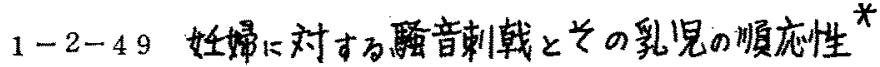

\section{。安藤四一(神大・I) 服部浩(神大・医)}

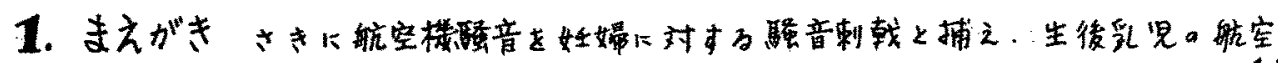

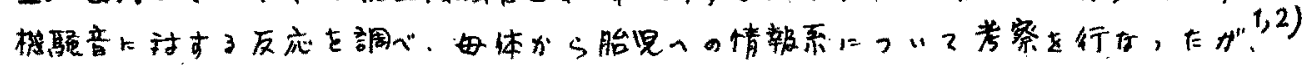
今回より多く、データを集みることができたのできのデータ、七合世韩告する。

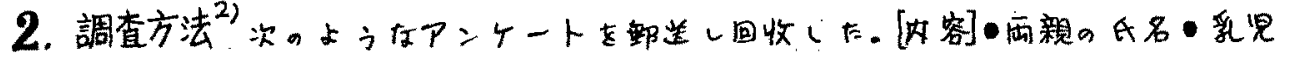

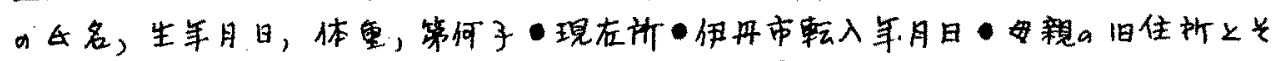

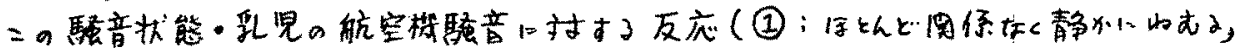

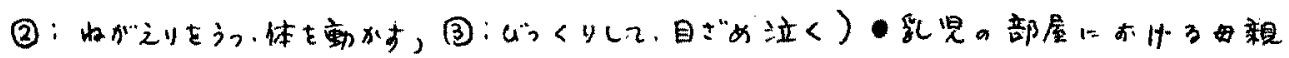

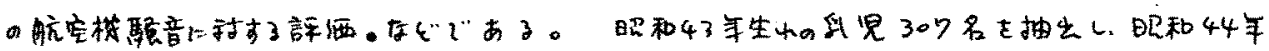

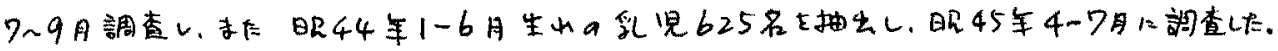

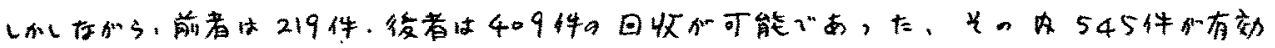

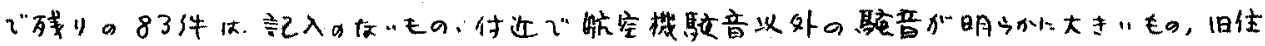

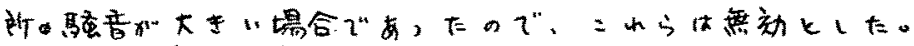

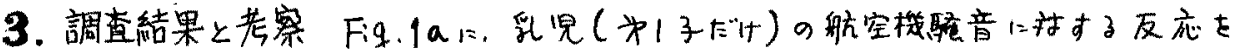

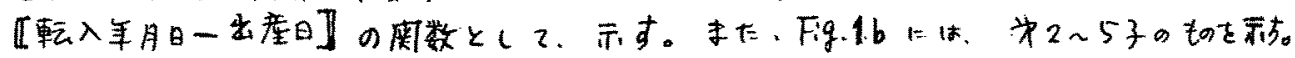

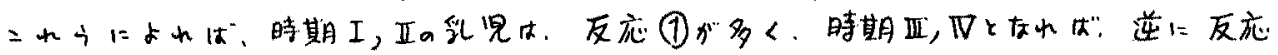

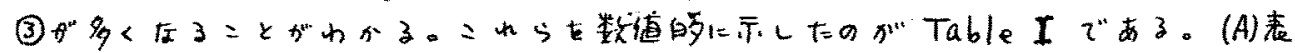

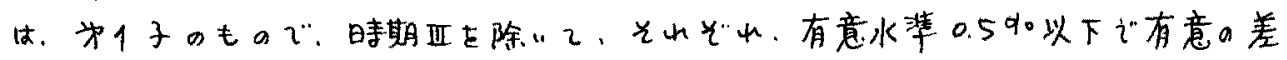

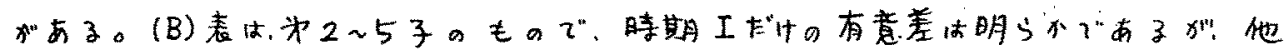

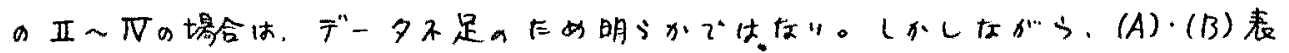

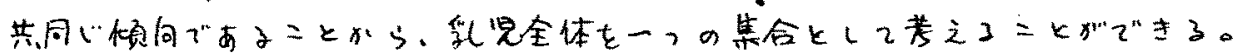

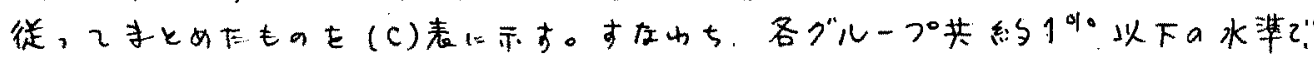
上記のような有意差があることが明らかである・故に、时期正が项への急激厉反

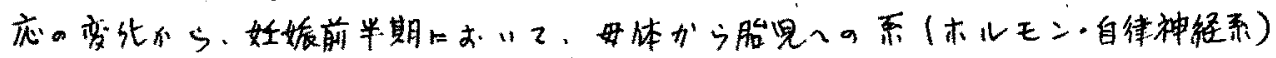

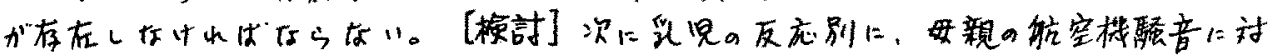

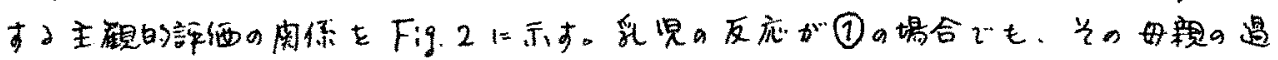

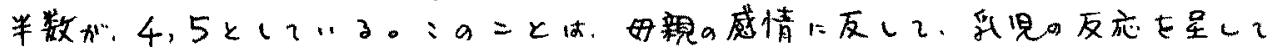

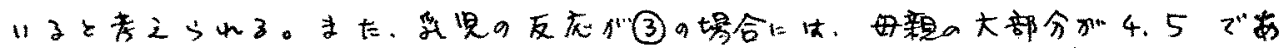

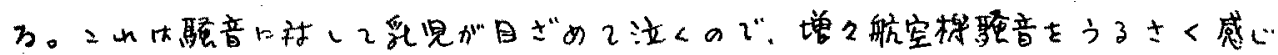

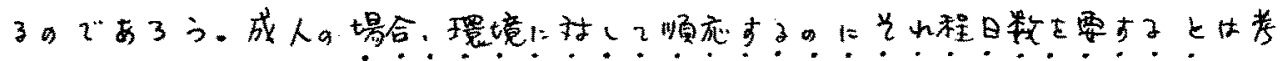

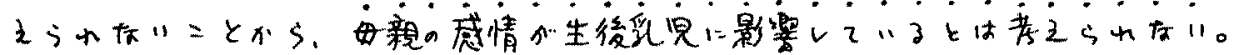

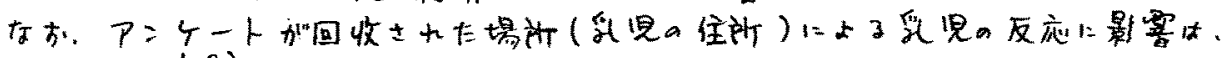

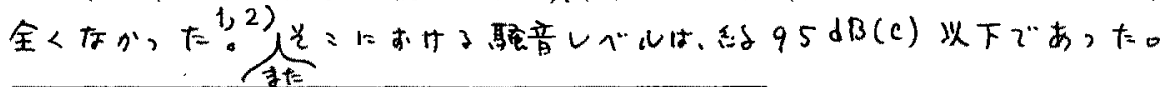

*Effects of Noise during Foetal Life upon Postnatal Adaptability (II). By Y.Ando (Faculty of Engineering, Kobe Univ.) and H. Hattori (Faculty of Medicine, Kobe Univ.) Rep.Japan Audiological Soc., Nov., 1970. 

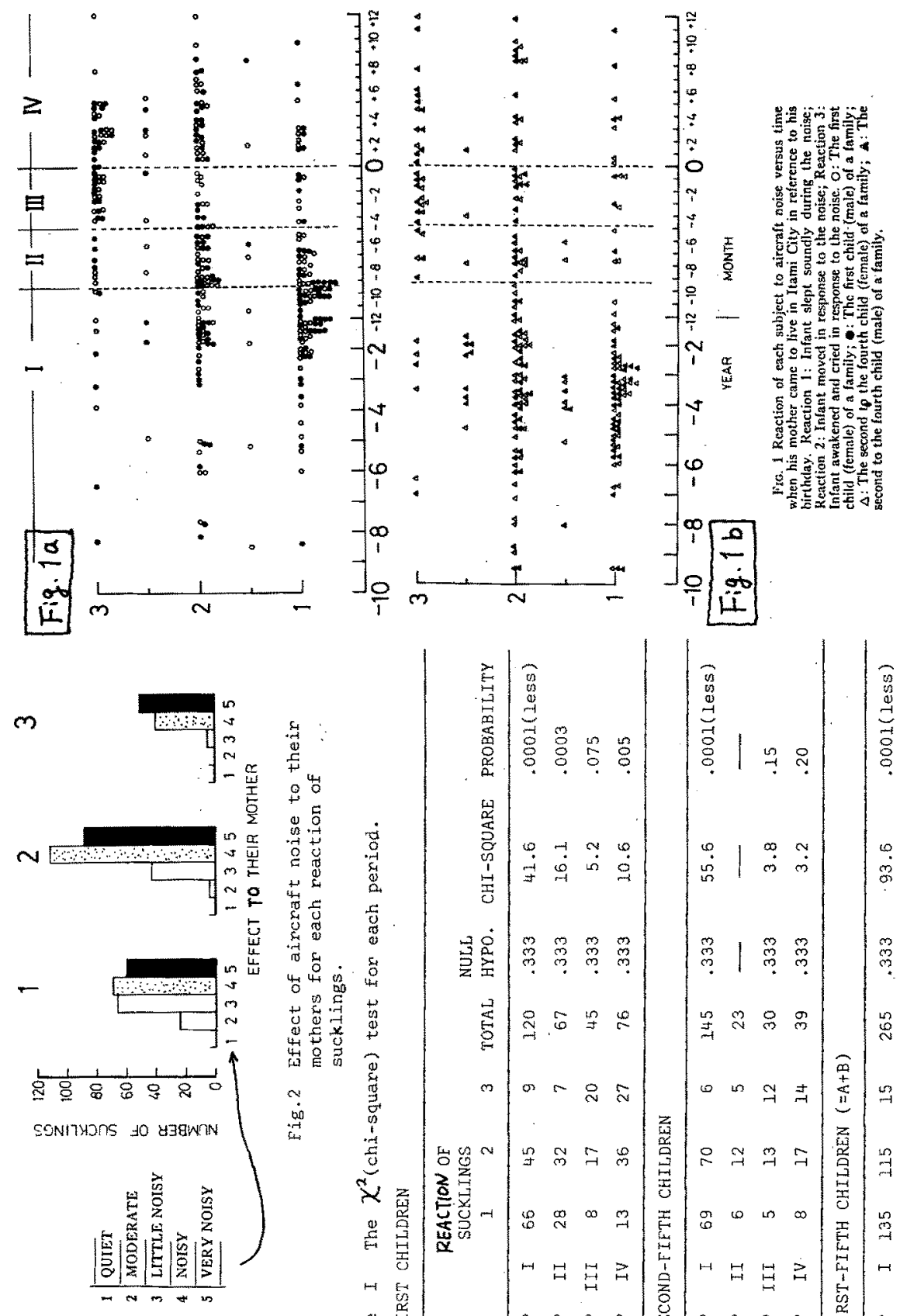

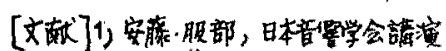

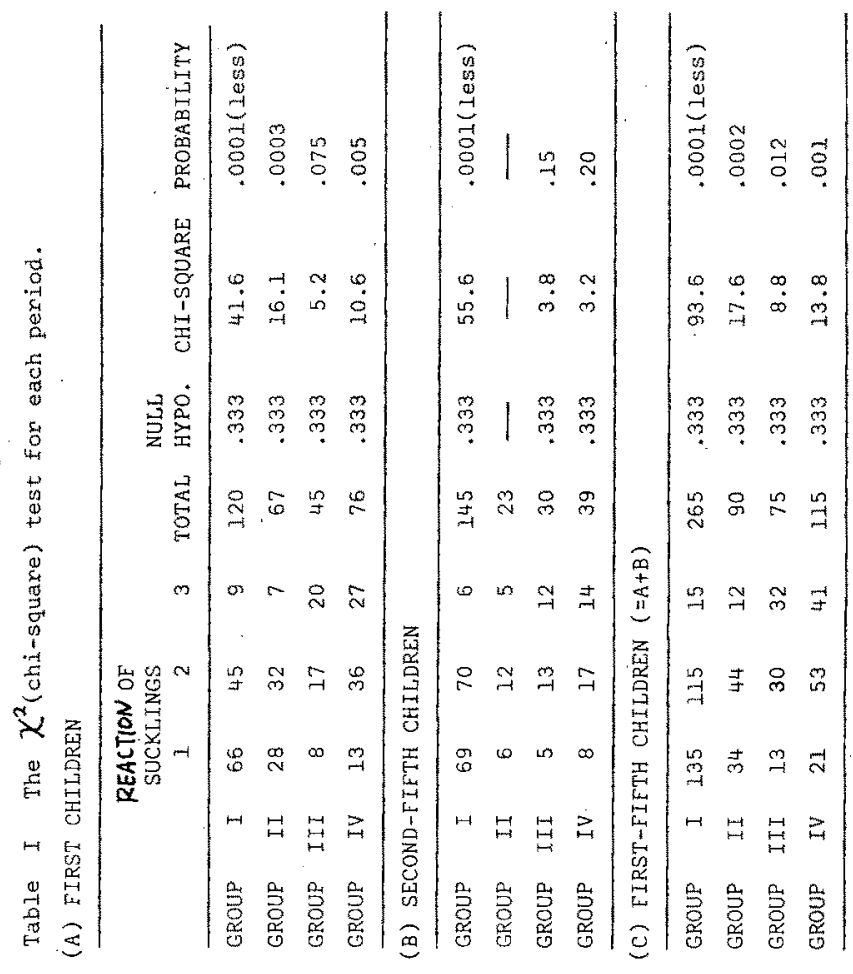

敦文係(Oct., 1969) P.7I

2) Y. Ando and H. Hattor:, J. Acoust. Soc. Amer, 47 (1970) P.1128.

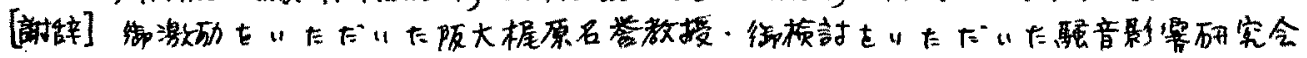

の方々に深く感謝します。また調查担当の山角さん。抽出に便宣を与之乙下さる伊

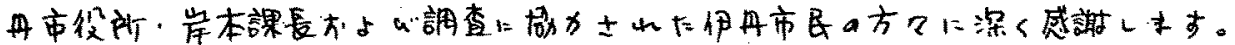

